\title{
Polymer Change Approach for Formulation of Aceclofenac Sustained Release Tablet
}

\author{
Nageshwar Malviya ${ }^{1}$, Miss. Sunita Sonartiya ${ }^{2}$, Mrs. Sunita Patidar ${ }^{2}$, Pranay \\ Sethiya $^{3}$, Apurva Joshi ${ }^{3}$, Kajal Mudgal ${ }^{4}$, Diksha Khateek ${ }^{4}$ \\ Swami Vivekanand College of Pharmacy, Indore, M.P., India
}

Article Info: Received 10 January 2022; Accepted 10 February 2022

DOI: https://doi.org/10.32553/jbpr.v11i1.897

Address for Correspondence: Nageshwar Malviya

Conflict of interest statement: No conflict of interest

\section{ABSTRACT:}

Aceclofenac is a non-steroidal anti-inflammatory drug (NSAID) analog of diclofenac. Aceclofenac works by inhibiting the action of cyclooxygenase (COX) that is involved in the production of prostaglandins (PG) which is accountable for pain, swelling, inflammation and fever. Modified drug delivery system has been used to improve the drug absorption and bioavailability. Sustained release tablet of Aceclofenac has been prepared with the help of different polymers for better results. In this review article, a new approach has been studied for the formulation of sustained release tablet of Aceclofenac by changing the polymers. Different polymers has been studied for the formulation of Aceclofenac SR tablet which shows better absorption and improved bioavailability. This suggests that marketed formulations of Aceclofenac tablet should be prepared and evaluated with this new approach for better results.

Keywords: Aceclofenac, Sustained release, Modified release drug delivery, Polymer, Absorption, Bioavailability

\section{Introduction}

\subsection{Oral drug delivery system}

An ideal drug delivery system should aid in the optimization of drug therapy by delivering an appropriate amount to the intended site and at a desired rate. Hence, the DDS should deliver the drug at a rate dictated by the needs of the body over the period of treatment. An oral drug delivery system providing a uniform drug delivery can only partly satisfy therapeutic and biopharmaceutical needs, as it doesn ${ }^{\text {ee }} \mathrm{t}$ take in to account the site specific absorption rates within the gastrointestinal tract (GIT). Therefore there is a need of developing drug delivery system that release the drug at the right time, at the specific site and with the desired rate ${ }^{1}$.

\subsection{Drawbacks associated with conventional dosage forms}

1. A drug with short biological half life which needs a close succession administration is required, so it may increase the missing of dosage form leads to Poor patient compliance.

2. The uncontrollable fluctuation of drug level may leads to either below effective range or over the effective range.

3. Plasma concentration verses time profile of dosage form and it ${ }^{\text {ee }}$ difficult to achieve the steady state active drug level. 
4. The rise and fall of drug levels it may give to accumulation of adverse effects especially for a drug having less therapeutic index.

\subsection{Sustained release drug delivery system}

The main destination of any drug delivery system is to furnish a contributing to quantity of a drug to a suitable region in the body and that the required drug concentration can be attained promptly and then being maintained. The drug delivery system should distribute a drug at a rate dictated by the require of the body for particular length of time. Regarding this existing points there are two important aspects to delivery system, said as, spatial placement and temporal delivery. Spatial placement connected to targeting a drug to particular organ, tissues, cells, or even sub cellular area; whereas temporal delivery system deals to controlling the rate of dosage form to the targeting region.

Sustained release tablets and capsules are mostly taken only once or twice daily, compared with immediate release tablet form that may have to take 3 or 4 times. Sustained Release Tablets a day to attain the same required drug to produce the effect. Typically, the sustained release dosage form to furnish at once release the active component that give the what we are desired for cure of disease, followed by remaining quantity of drug should be release and maintained the therapeutic effect over a predetermined length time or prolonged period. The sustaining of drug plasma levels furnish by sustained release dose often times to eliminate the require for night dose administration, which suitable not only the patient but the care given as well.

The bulk of research can be focusing toward oral dosages that improve the temporal aspect of drug delivery. This approach is a continuously developing in the pharmaceutical industry for sustained release oral drug delivery system. The sustained release system for oral use of administration are mostly solid and based on dissolution, diffusion or a combination of both, erosion mechanisms, in the power to directing the drug release. A delivery system containing hydrophilic and hydrophobic polymers and waxes are mixed with active component to furnish drug action for a prolonged length of time $^{2}$.

\subsubsection{Advantages of sustained release drug delivery system}

1. Reduction in dosing frequency.

2. Reduced fluctuation in circulating drug levels.

3. Increased patient convenience and compliance.

4. Avoidance of night time dosing.

5. More uniform effect.

6. Maximum utilization of drug.

7. Reduction in GI irritation and other side effects.

8. Reduction in health care cost through improved therapy.

9. Improve bioavailability of some drugs ${ }^{3}$.

\subsubsection{Disadvantages of sustained release drug delivery system}

1. Decreased systemic availability in comparison to immediate release conventional dosage form. This may be due to

$>$ Incomplete release

$>$ Increased first-pass metabolism,

$>$ Increased instability

$>$ Site specific absorption, $\mathrm{pH}$ dependant solubility, etc.

2. Poor in vitro-in vivo correlation.

3. Possibility of dose dumping.

4. Retrival of drug is difficult in case of toxicity, poisoning, or hypersensitivity reactions.

5. Higher cost of formulation.

\section{Aceclofenac Drug Profile}

Aceclofenac is a non-steroidal antiinflammatory drug (NSAID) analog of diclofenac. It is used for the relief of pain and inflammation in rheumatoid arthritis, osteoarthritis and ankylosing spondylitis. 
It was patented in 1983 and approved for medical use in 1992.

Aceclofenac should not be given to people with porphyria or breast-feeding mothers, and is not recommended for children. It should be avoided near term in a pregnant woman because of the risk of having a premature closure of ductus arteriosus leading to fetal hydrops in the neonate.

It is practically insoluble in water with good permeability. It is metabolized in human hepatocytes and human microsomes to form [2(2',6'-dichloro-4'-hydroxy- phenylamino) phenyl] acetoxyacetic acid as the major metabolite, which is then further conjugated. According to the Biopharmaceutical
Classification System (BCS) drug substances are classified to four classes upon their solubility and permeability. Aceclofenac falls under the BCS Class II, poorly soluble and highly permeable drug.

Aceclofenac works by inhibiting the action of cyclooxygenase (COX) that is involved in the production of prostaglandins (PG) which is accountable for pain, swelling, inflammation and fever. The incidence of gastric ulcerogenicity of aceclofenac has been reported to be significantly lower than that of the other frequently prescribed NSAIDs, for instance, 2folds lesser than naproxen, 4-folds lesser than diclofenac and 7-folds lesser than indomethacin ${ }^{4}$.

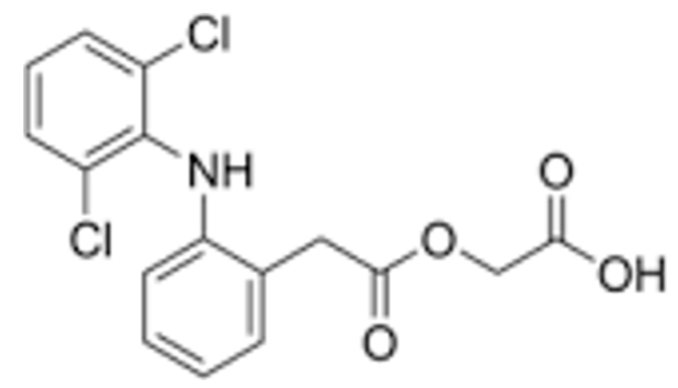

Fig. 2.1 Structural formula of Aceclofenac

\section{Properties:}

Official:- In Indian pharmacopoeia

Molecular Formula:- $\mathrm{C}_{16} \mathrm{H}_{13} \mathrm{C}_{12} \mathrm{NO}_{4}$

Molecular Weight:- 354.19

Chemical Name:- (2,6dichlorophenyl)aminophenylacetoxyacetic Acid

Solubility:- Drug is freely soluble in acetone and insoluble in water

Appearance:- White or almost white powder

Shape:- Crystalline Powder

Identification:- when examined in the range of $220 \mathrm{~nm}$ to $370 \mathrm{~nm}$. The $0.002 \% \mathrm{w} / \mathrm{v}$ solution in methanol show Maximum absorption at $275 \mathrm{~nm}$ It contain not less than $99 \%$ not more than $101.0 \%$ Of its compounds calculated on the dried basic.
Biopharmaceutical:- Class IInd (high permeability and low solubility)

Uses:

- Aceclofenac is used for pain relief.

- It relieves pain and inflammation in conditions like rheumatoid arthritis, ankylosing spondylitis, and osteoarthritis.

- In acute lumbago.

Aceclofenac SR tablet are available at strength $200 \mathrm{mg}$ or $250 \mathrm{mg}$ dose in market ${ }^{5}$.

3. Improved absorption approach for Aceclofenac Sustained Release Tablet

The absorption of the Aceclofenac sustained release tablet can be improved selectively by changing the polymer in the formulation of Aceclofenac Sustained Release tablet.Some of 
the polymers that can be used to enhance the absorption are described below:-

\subsection{Hydroxypropyl Methylcellulose}

Hydroxypropyl methylcellulose (HPMC) is a semisynthetic, inert, viscoelastic polymer used as eye drops, as well as an excipient and controlled-delivery component in oral medicaments, found in a variety of commercial products $^{6}$.

\section{Properties:}

Empirical formula:- $\mathrm{C}_{8} \mathrm{H}_{15} \mathrm{O}_{6}-\left(\mathrm{C}_{10} \mathrm{H}_{10} \mathrm{O}_{6}\right) \mathrm{n}-$ $\mathrm{C}_{8} \mathrm{H}_{15} \mathrm{O}_{5}$

Description:- it is odorless tastless, white or creamy white fibrous or granular powder.

Molecular weight:- 86,000

Bulk density:- $0.25-0.75 \mathrm{~g} / \mathrm{cm}^{3}$

Viscosity 2\% solution:- HPMC K100M 80000-120000 cps, HPMC K15M -1125021000 cps, HPMC K4M -3000-5000 cps

Incompatibility:- extreme $\mathrm{pH}$ condition oxidizing material

\section{Uses :}

1. It is used to treat medical conditions characterized by insufficient tear production such as kerato conjunctivitis sicca), recurrent corneal erosions, decreased corneal sensitivity, exposure and neuroparalytic keratitis.

2. HPMC is also used as a lubricant for artificial eyes.

3. HPMC is used as a thickener, a low level binder and as an emulsion stabiliser with $\mathrm{E}$ number E463.

4. In pharmaceuticals it is used as a binder in tablets.

5. HPMC is used as a sieving matrix for DNA separations by capillary and microchip electrophoresis.

\subsection{Microcrystalline Cellulose}

Microcrystalline cellulose (MCC) is a term for refined wood pulp and is used as a texturizer, an anti-caking agent, a fat substitute, an emulsifier, an extender, and a bulking agent in food production.

The most common form is used in vitamin supplements or tablets.

It is also used in plaque assays for counting viruses, as an alternative to carboxymethylcellulose ${ }^{7}$.

Properties:

Synonym:- Avicel, crystalline cellulose emcocel

Molecular formula:- $\quad(\mathrm{C} 6 \mathrm{H} 10 \mathrm{O} 5) \mathrm{n}$ or C12H22O11

Molecular weight:- $342.3 \mathrm{~g} / \mathrm{mol}$

Purity:- 99\%

Appearance:- white powder

Melting point:- 500 to $518^{\circ} \mathrm{F}$ (Decomposes)

Formulation:- A neat solid

Incompatibility:- incompatible with strong oxidizing agent

Application:- MCC has use in cosmetics as an abrasive, absorbent, anti-caking agent, aqueous viscosity increasing agent, binder, bulking agent, emulsion stabilizer, slip modifier, and texturizer,which can be found in various hair and skin care products as well as makeup. The MCC is a valuable additive in pharmaceutical, food, cosmetic and other industries.

\subsection{Magnesium Stearate}

It is also called metallic stearate. Chemically it is octadecanoic acid. Its a simple salt made up of two substances, a saturated fat called stearic acid and the mineral magnesium. Stearic acid can also be found in many foods ${ }^{8}$.

\section{Properties:}

Chemical formula: $-\mathrm{Mg}\left(\mathrm{C}_{18} \mathrm{H}_{35} \mathrm{O}_{2}\right)_{2}$

Molar mass:- $591.27 \mathrm{~g} / \mathrm{mol}$

Appearance:- light white powder

Odor:- slight

Density:- $1.026 \mathrm{~g} / \mathrm{cm} 3$ 
Melting point:- $88.5^{\circ} \mathrm{C}\left(191.3^{\circ} \mathrm{F} ; 361.6 \mathrm{~K}\right)$

Solubility in water:- $0.003 \mathrm{~g} / 100 \mathrm{~mL}\left(15^{\circ} \mathrm{C}\right)$, $0.004 \mathrm{~g} / 100 \mathrm{~mL}\left(25^{\circ} \mathrm{C}\right), 0.008 \mathrm{~g} / 100 \mathrm{~mL}\left(50^{\circ} \mathrm{C}\right)$

Solubility:- negligible in ether and alcohol

slightly soluble in benzene

\section{Uses:}

Magnesium stearate is often used as an antiadherent in the manufacture of medical tablets, capsules and powders. In this regard, the substance is also useful because it has lubricating properties, preventing ingredients.

\subsection{Carbomer 934 P}

It is a high molecular weight polymer of acrylic acid linked with allyl ether of sucrose. It is having different variant of grade that are in such a manner ${ }^{9}$.

$>$ It is a dried in vaccum at $80^{\circ} \mathrm{C}$ for 1 hours.

$>$ It contains not less than $56.0 \%$ not more than $68 \%$ of $\mathrm{COOH}$ groups .

$>$ The viscosity of neutralized $0.5 \%$ aqueous dispersion of carbomer $934 \mathrm{P}$ is between viscosity of this is between $29,400 \& 39,400$ centipoises.

\section{Application}

$>$ Sustained release

$>$ Site specific drug delivery to esophagus

$>$ Matrix beads

$>$ Additionally used in preparation of SR tablet. By used dry or wet binder as rate controlling excipient.

\subsection{Colloidal Silicon Dioxide}

Silicon dioxide, also known as silica, is an oxide of silicon with the chemical formula $\mathrm{SiO} 2$, most commonly found in nature as quartz and in various living organisms.

\section{Properties:}

Molecular Formula:- $\mathrm{SiO}_{2}$ or $\mathrm{O}_{2} \mathrm{Si}$

Molar mass:- $60.08 \mathrm{~g} / \mathrm{mol}$

Appearance:- Transparent solid (Amorphous) White/Whitish Yellow

Density:- 2.648 ( $\alpha$-quartz), 2.196 (amorphous) $\mathrm{gcm}^{-3}$
Melting point:- $1,713{ }^{\circ} \mathrm{C}\left(3,115^{\circ} \mathrm{F} ; 1,986 \mathrm{~K}\right)$ (amorphous)

Boiling point:- $2,950{ }^{\circ} \mathrm{C}\left(5,340{ }^{\circ} \mathrm{F} ; 3,220 \mathrm{~K}\right)$

\section{Application}

It is used primarily as a flow or anti-caking agent in powdered foods such as spices and non-dairy coffee creamer, or powders to be formed into pharmaceutical tablets.

$>$ It can adsorb water in hygroscopic applications.

$>$ Colloidal silica is used as a fining agent for wine, beer, and juice ${ }^{10}$.

\subsection{Ethyl Cellulose}

Ethyl cellulose (EC) is an important commercial cellulose derivative where ethoxy groups have replaced hydroxyl groups on the repeating glucose units. Ethyl cellulose finds uses in foodpackaging applications and as a barrier coating for controlled drug release of pharmaceutical products $^{11}$.

\section{Properties:}

Solubility: in freely soluble in ethanol, in methanol, in toluene, in chloroform, and in ethyl acetate.

Molecular Weight: 454.5

Melting temperature : $240-255^{\circ} \mathrm{C}$

\section{Application:}

D This polymer has excellent strength at room temperature but its strength decreases rapidly with increasing temperature.

$>$ Like methyl cellulose, it has excellent UV resistance, and is soluble in many organic solvents but not in nonpolar solvents such as aliphatic hydrocarbon oils, natural oils, and greases.

$>$ Ethyl cellulose finds uses in food-packaging applications and as a barrier coating for controlled drug release of pharmaceutical products.

$>$ Ethylcellulose is used in pharmaceutical technology as a coating agent, flavoring 
fixative, binder, filler, film-former, drug carrier, or stabilizer.

\section{Discussions}

The Sustained Release tablets of Aceclofenac has shown promising results for better absorption and efficacy. The polymer change approach could also be used to improve the absorption of Aceclofenac Sustained Release tablet. The polymers hydroxypropyl methylcellulose, microcrystalline cellulose, magnesium stearate, carbomer $934 \mathrm{P}$, colloidal silicon dioxide and ethyl cellulose have shown great potential to be used in the formulation of Aceclofenac SR tablet. Various research have been made on the topic which clearly shows better efficacy and absorption of the drug.

\section{References}

1. Ashok V. Bhosale, Rahul V. Takawale, sanjay D. Sawamy "oral novel drug delivery system "The Eastern pharmacist", September 2000, 41- 43 Pp.

2. Ansel's "Pharmaceutical dosage forms and Drug Delivery System", loyd V. Allen,Jr, Nchols G. Popovich, Howard C. Ansel, 8th edition, 260-275 Pp.

3. D. M. brahmankar, Sunil B. Jaiswal "Biopharmaceutics and Pharmacokinetics a Treatise, 2002 reprint, Vallabh prakashan, 335-33 Pp.

4. Thomas Wai- Yip Lee, Joseph R. Robinson, 'Controlled- Release Drug- Delivery
Systems,' Chapter-47 in Remington: "The science and practice of pharmacy", 20th edition, vol-1, $903 \mathrm{Pp}$.

5. N.K. Jain, "Advances in Controlled and Novel Drug Delivery", CBS publications, 268-269 Pp.

6. Oral extended release product lioydn, sanson, head, school of pharmacy and medical sciences, university of South Australia, Adelaide, Aust Preeser 1999, 22:88-90 Pp.

7. Thomas wai-Yip lee, Joseph R. Robinson, controlled-release drug delivery system's, chapter - 47 in Remington "The Science and Practice of Pharmacy", 20th edition, vol-1, 303, 907-910 Pp.

8. N.K. Jain, "Advances in controlled and Novel Drug Delivery", CBS publications, 268-269 Pp.

9. Hamed M. Abdou, "Dissolution characteristics of controlled Release systems", chapter -12 in "Dissolution Bioavailability and bioequivalence," 215$218 \mathrm{Pp}$.

10. Leon Lachman, Herbert A. Liberman, Joseph L. Kanig, "The Theory and Practice of Industries Pharmacy", 3rd edition.

11. S.K.Baveja, A.V.Hassan and Amarjet Singh, "zero order release of pseudoephdrine hydrochloride from hydrophilic matrix tablets". Indian journal of pharmaceutical, sciences November - December 1989: 248 $251 \mathrm{Pp}$. 